\title{
The Rational Foraging Terrorist: Analysing the Distances Travelled to Commit Terrorist Violence.
}

- "Take a good look at it [the neighbourhood], Rick. If we go ahead with the job, we're not goin' to be seein' it for a long time". Dollhead said.

- "What makes ya think we'll not be seein' it for a long time?"

- "Cause this job's a fuckin' suicide mission! Rick, have ya done a dummy run on it?"

- 'Nah, I haven't. Jesus Christ, Dollhead, this isn't like you at all. It can't be that bad, surely. Fuck sake, it's just a shitty oul' bank robbery!"

- "Shitty oul' bank robbery, my balls! Rick, I swear to God, it is that bad, an' worse. Have ya any idea how far away Mallusk is?"

This conversation opens Rick O'Rawe's ${ }^{1}$ autobiography on life within the Provisional Irish Republican Army (PIRA). It provides some insight into a dilemma long researched within the volume crime literature but overlooked within the terrorism studies field. Offenders rationally optimize between targets. Considerations of issues like security, avoiding detection, clean getaways and an awareness of how vulnerable targets are stratified are regularly engaged upon. Crime pattern theory analyses how criminals deal with some of these dilemmas. The theory focuses upon the distribution of targets and crime site selection in relation to the offender's home-space, anchor points and daily routines. A key principle is that all individuals learn about their immediate environment through everyday conventional activities. Offenders rely upon these conventional activities (which themselves create 'awareness space') to ease aspects of their offense 
such as choosing targets, the timing of offences and getaway plans. Empirically, these assertions have been validated and the findings largely illustrate that crime trips typically involve short distances and this has been replicated across a range of crimes such as car theft, homicide, juvenile assault, rape, robbery (commercial and non-commercial), residential burglary and vandalism (see Townsley and Sidebottom for a review). ${ }^{2}$ Other studies have found significant differences in the average distance of journey to crime across offender demographics ${ }^{3}$ and offences. ${ }^{4}$

These studies beg the question however, whether this same behavioural trait applies to terrorists? On the one hand, there is a growing voice within the criminology literature that criminological paradigms apply to terrorism. ${ }^{5}$ Typically however these empirical studies focus on terrorist events rather than the actors who commit them. Consequently, we know very little about terrorist behaviour at the individual actor level. On the other hand, terrorism (in terms of its outcome) is very different than most volume crime. If an offender chooses to engage in an indiscriminate, possibly highly fatal, act of violence, it may make more sense to travel further away from home in order to minimize the chances that a victim is a friend or family member.

This paper applies the distance-to-crime approach to the case of Improvised Explosive Device (IED) and shooting attacks conducted by the Provisional Irish Republican Army (PIRA) during the Northern Ireland conflict, 1970-1998. The aim is to (a) measure the typical 'distance to crime' (b) detect whether a distance-decay effect is noticeable and (c) investigate whether there is a discernible difference in the distance travelled depending 
upon individual offender characteristics or aspects of how the offence was committed. This approach is very important to the behavioural study of the terrorist. The barbarity of terrorist atrocities, coupled with the fact that participation in terrorism is characterized by an extremely low base rate, has led researchers to seek out individual qualities of the terrorist such as personality factors. This search has proven unproductive and impractical. In fact, it has most likely limited and unduly narrowed a wider consideration of the ways in which social scientists can bring what conceptual tools we have to bear on the problem of controlling and managing terrorist behaviour. ${ }^{6} \mathrm{We}$ shift the focus from individual qualities (what we think terrorists "are") to a consideration of the situational qualities of terrorists' behaviour - in other words, what terrorists do and how they do it. ${ }^{7}$ This approach is consistent with developments in the area of crime control. ${ }^{8}$ In criminology, the situational crime perspective developed in response to efforts to explore similar issues - to prevent criminal activity, do we focus on changing some aspect of the offender, or do we look to the qualities associated with the offence (and thereby attempt to reduce the opportunity for offenders to engage in criminal activity).

\section{The Rational Foraging Terrorist}

This paper builds on a commonly held belief that terrorism is a purposeful behaviour guided by a form of rational choice. Rationality, in this sense, is bounded by time, effort, experience, knowledge, which in turn feed into the weighting of rewards, costs and alternative action plans. ${ }^{9}$ Such rational calculations may include having to choose between terrorist tactics and opting for the strategically most advantageous. Pape's work on suicide terrorism is probably the most oft-cited example of such an approach. ${ }^{10}$ 
Rational calculations are also framed by the group's ideological content and therefore targeting practices may differ across the ideological spectrum. For example, Drake notes that a terrorist organization's ideology relates to targeting practices because "it sets out the moral framework within which they operate". ${ }^{11}$

A continuingly overlooked aspect of such rational calculations however is at the level of individual terrorist behaviour. For example, the choice of particular individuals for particular tasks is perhaps not random. For example, Perliger, Koehler-Derrick and Pedahzur analysed 331 Jihadists. Those directly engaged in violent activities were significantly more likely single, unemployed, and not an immigrant than those who participated in purely facilitative activities. ${ }^{12}$ Gill and Young also illustrated that suicide bombers tend to be younger and less educated than other individuals engaged in other terrorist roles. ${ }^{13}$ Also, the offence-commission behaviours of individuals (for example the choosing of specific targets) are also not likely to be random. Much of the criminology literature depicts such offender behaviour as being akin to foraging. For example, some foraging principles depict burglars as "predators who search for patches, preferably close to their nest, where nutritious prey are abundant, cannot flee, and are less vigilant." ${ }^{" 14}$ In the case of PIRA, organizational elites set the broad agenda of what were viable target types but often small-scale attacks on specific targets were plotted, hatched and executed at the local level. Given such a broad remit to commit offences, individual decisions behind who specifically to target were related to opportunity costs, experience, expertise and timing at the local recruit level. ${ }^{15}$ 


\section{Sometimes Smaller is Better: The Rationality of Distance Travelled}

One quality of foraging behaviour is the decision concerning how much travel should be undertaken for the commission of the offence. Existing research on the distance to crime illustrates that the typical distance covered is very small. For example, Amir's research on rapists illustrated that $82 \%$ lived in the same neighbourhood as their victims. ${ }^{16} \mathrm{Le}$ Beau's sample of serial sexual offenders, on average, travelled less than a mile to commit their offense. ${ }^{17}$ Warren et al.'s study of serial offenders shows they travelled an average of three miles to offend. ${ }^{18}$ First hand interview accounts with offenders highlight some of the reasoning behind this particular type of behaviour. ${ }^{19}$

Theoretically, such research is usually explained using Zipf's least effort principle. ${ }^{20}$ Heavily influenced by rational choice perspectives, the least effort principle assumes that given a "number of identical alternatives for action, an offender selects the one closest to him in order to minimize the effort involved". ${ }^{21}$ All individuals have a range of routine daily activities that they carry out which are non-criminal. Typically these nodes of activity can be anything concerned with their home-place, work, schooling, shopping or entertainment. In order to commit a crime, in this case an IED event or shooting attack, the individual must locate a target or victim. Crime pattern theory contends that in choosing a specific target, it is far more likely to occur somewhere along the path between the individual's activity nodes because this area encapsulates his/her 'awareness space' of identifiable vulnerable targets coupled with getaway routes. 
Racial or ethnic barriers may also further restrict an individual's willingness or capability to travel further from their home to commit an offence.

"For individuals who participate in legal activities, moving into unknown terrain may be an unpleasant experience, but for individuals who plan illegal activities, it may be outright dangerous. Strangers 'stand out' more easily in unknown territory, that is, in places where they do not know the customs and rules of the street and possibly dress and behave in ways that attract the attention of the local residents...In segregated cities, those who cross racial or ethnic boundaries cannot blend in easily are likely to be recognized as strangers in the community and be subjected to the 'social eyes' of the local population'. ${ }^{22}$

Such concerns were apparent for organizational decision making within the Palestinian conflict. Bloom argues that groups were more likely to choose educated or female individuals to conduct suicide terrorism operations within Israel because their language skills and looks would fit in more easily within Israeli society and not draw as much attention. ${ }^{23}$ Given the high levels of ethnic residential segregation within Northern Ireland coupled with the high number of indicators used by both sides of the Northern Ireland conflict to identify members of the opposite side (see the lifetime work of Ed Cairns for example), it may be expected that operations rarely went 'deep' into enemy territory but rather stayed rather close to the boundaries of 'home-soil'.

A further consistent empirical finding within this literature is that an offender's typical journey to crime can be depicted as a distance decay function; as distance from home increases, the chances of offending decreases. ${ }^{24}$ Theoretically, the explanation for this finding is similar to the above paragraph; "people interact more with people and things that are close to their home location than with people or things that are far away" and therefore a repeat criminal offender's crime events will decrease the further in distance 
from the offender's homestead. ${ }^{25}$ This function has been demonstrated previously in a terrorism context in Turkey. ${ }^{26}$ Smith, Damphousse and Roberts however found a bimodal distribution amongst a sample of individuals convicted of terrorism offences in the United States (46\% travelled less than 30 miles; 37\% travelled over 271 miles). This finding was driven by those individuals within the sample attached to international, leftwing, and single-issue terrorism. Right-wing terrorists bucked the trend. Given the fact that ethno-national terrorism in Turkey more closely resembles Irish Republican terrorism in terms of goals, motivation and frequency of attacks, we derive the following hypothesis. ${ }^{27}$

\section{H1: The distance travelled to the attack site by a sample of terrorist offenders will reflect a distance-decay function}

\section{Not All Offenders and Offences are Identical}

Existing research finds key differences in travelling patterns once the type of crime and individual characteristics of the offender are disaggregated. Beauregard et al.'s review of the sex offender literature shows distinct differences in the travel distance of sex offenders depending upon age (older offenders travel further), the complexity of the offence (if additional offences such as burglary occur distances decrease), timing (weekend offenders travel further), experience (repeat offenders travel further), and location (sexual offences that occur outside typically take place further away from the offenders home). ${ }^{28}$

The existing literature largely finds that younger criminal offenders typically travel shorter distances to commit their crime. ${ }^{29}$ Further, Goodwill and Allison's work on repeat 
offenders across a range of crimes illustrates that they gradually increase their travel distances over time. While initial offences occur relatively close to home, Goodwill and Allison illustrate that "subsequent offences are committed further and further away" and that this is largely due to the offender increasing his/her experience and confidence in crime commission. ${ }^{30}$ Briggs assumes that this is due to younger individuals having fewer social ties outside of their home area. Others suggest that older offenders have access to vehicles thus facilitating longer journeys. ${ }^{31}$

\section{H2: Younger terrorists travel shorter distances in the commission of their attack}

The nature of the target and attack type may also influence distance travelled. Whereas some targets may be more readily available and easier to identify (civilian targets) or be static (physical targets, including businesses), others may necessitate fine-tuned intelligence and event planning because the target is harder to identify (off-duty police officers) or is constantly on the move and changing their daily routines (military convoys). The difficulty of accessing and pinpointing particular targets may therefore necessitate the need to travel further or accommodate last-minute changes. Existing research has also shown that (a) traditional criminological studies on victimisation are

worthwhile in a terrorism context ${ }^{32}$ and that (b) crimes that require greater planning typically also tend to involve longer distances. ${ }^{33}$ We may therefore also see significant differences across attack types.

\section{H3: Terrorist attacks against high-value targets involve longer travel distances \\ H4: Complex events that involve parallel terrorist involve longer travel distances}


Finally, the organisational set-up within which offenders operated may also impact upon their decision-making regarding an offence. The Provisional Irish Republican Army, for example, went through a period of re-organization from 1977 to 1980. PIRA leaders outlined the necessity for, and implications of, reorganisation in an internal document entitled the "Staff Report". The document outlined a number of highly researched changes including a new departmental structure, ${ }^{34}$ a new cell structure,,${ }^{35}$ the new roles for

PIRA's female and youth wings, ${ }^{36}$ the development of a new auxiliary unit, ${ }^{37}$ and a new front line role for political wing, Sinn Fein. ${ }^{38}$ Collectively these changes placed a greater emphasis on internal secrecy and stricter discipline. ${ }^{39}$ However, one of the report's suggestions remains overlooked and untested. In the section regarding cell reorganisation, it outlines that "Cells should operate as often as possible outside of their own areas; both to confuse Brit Intelligence (which would thus increase our security) and to expand our operational areas". We are therefore interested in whether PIRA members travelled greater distances to their attack location post-reorganisation.

\section{H5: Terrorist attacks involved greater travel distances after PIRA's reorganisation was completed in 1980}

\section{Data}

The original database contains information on 1240 individuals who were either convicted of PIRA-related activities (including membership) or died on 'active service', a term used by PIRA to describe members' involvement. ${ }^{40}$ The emphasis in the initial data collection was to find 'core' members of the group for a social network analysis. ${ }^{41}$ These core individuals were identified from a number of open sources (1) Statements by PIRA including their annual Roll of Honour which commemorates their war dead (2) The 
Belfast Graves (1985) publication that offers an account of Republicans killed in combat (3) McKittrick et al.'s 'Lost Lives' which provides an obituary of each civilian and (para)military victim of the Northern Ireland conflict ${ }^{42}$ (4) Historical accounts of PIRA from academic sources (5) Newspaper archives. Their connections and their connection's connections were subsequently coded also. Two coders independently coded each individual in the dataset.

For each individual, the database captures 52 data points. The information captured includes name, a unique identifier number that anonymises the individual (also so that the database can eventually be made public to other researchers), alias, gender, highest level of education achieved, organizational affiliation, sub-unit affiliation, year of birth, age at earliest identifiable paramilitary activity, the phase of the conflict in which they took part in their first activity, the year of first identifiable activity, whether they were killed in combat (and if so, their age of death, the year of death and the phase of the conflict in which they died), their place of birth (whether it was North or South of the border, the province, the county, town/village size, urban/rural), their known address at time of activity they were convicted of (whether it was North or South of the border, the province, the county, town/village size, urban/rural), the coordinates of their known address at time of activity they were convicted of, marital status, whether they had children (and how many), occupation, occupation type, positions held within the organization (when they held them and at what age), years active, arrests ${ }^{43}$, prison terms, location of bombing event, co-ordinates of bombing event, date of bombing event, distance travelled from home address to bombing address, number of individuals killed in 
event, whether it was a lethal attack or not, number of individuals injured in event, whether the bombing event involved parallel terrorist activities, time of event, the bombing event's day of the week and the target type of the bombing event. The 'prerestructure' variable relates to whether the terrorist attack occurred before or after the shift in PIRA's network structure occurred. Following Asal et al., high-value targets encompassed a collection of Northern Ireland security forces such as the British Army, the Royal Ulster Constabulary (the Northern Ireland police force), the Ulster Defence Regiment, and the Royal Irish Regiment as well as government officials (both elected and unelected) and other political figures. ${ }^{44}$

For the purposes of this analysis, we sifted through each of these 1240 individuals for information on their conviction. We then omitted any individuals who were not convicted on a specific attack-related offense (e.g. many were convicted of simple membership not for having committed a specific attack at a specific location). We could tie 235 individuals to specific bomb-planting or shooting attacks on behalf of PIRA during the Northern Ireland conflict from 1970-1998. The address of the individual offender and the location of the offense are reported at the street level within newspaper articles in The Irish Times. For the geo-coordinates and distance-travelled measures we used the online application GPS visualizer (www.gpsvisualizer.com). This application calculates the straight-line distance between the offense location and home location of the offender. This measure is the most commonly used measure in the existing literature because there is no way of calculating the exact route taken by the offender in the commission of their attack. Evidence also suggests that offenders typically tend to think of distance in 
straight-line measurements rather than actual routes. ${ }^{45}$ The GPS coordinates for the middle of their street were utilised. Each individual is only included in the analysis once, thus overcoming the problem of nesting within the data Townsley and Sidebottom identified elsewhere. ${ }^{46}$

While the data are sufficiently large, reliable and dense for the analysis that follows, some caveats are appropriate. It is not a complete dataset of all PIRA members. Many PIRA members may have eluded convictions and hence escaped our data collection protocols. The observations are also non-random due to the original sources used to build the actor dictionary. There is no way therefore to estimate the effects that missing observations have upon the analysis that follows. Finally, the Irish Times archive is the sole newspaper source used for the database. For practical reasons (needing access to digitalized newspapers), we could not add other newspapers such as the Belfast Telegraph into our data collection capabilities. Such a source may have added data density to particular variables.

\section{Results}

Using the online application, GPS visualizer, we could identify the straight-line distance between two co-ordinates to the precision of two decimal points. For the sake of Figure 1, we rounded these figures downward. For example, the 61 cases under the category 0 in the below figure, travelled less than 1 mile. Those in category 1 , travelled less than 2 miles etc. Those who travelled more than 15 miles $(n=16)$ are excluded from the below figure. 
Insert Figure 1 Here

Typically, PIRA recruits did not travel far to engage in an attack. Nearly two-thirds of the sample (64.3\%) travelled less than four miles to engage in their attack. This reflects similar findings to the analogous cases mentioned above. There also appears to be a distance decay effect, confirming hypotheses 1 . The further the distance from home, the less likely the recruit is to engage in an attack. This decay appears to be even starker in the case of those engaging in a shooting attack with over $40 \%$ of these cases taking place within a mile of the offender's home. The decay kicks in a little later for the bomb planters. A small spike begins to emerge and subside around the 10-mile mark, and as we shall see below, this is largely related to who is targeted in the attack itself. The findings suggest that if the target is civilian, the closer to home the attack is likely to take place and this is largely because of the plethora of available civilian targets. However, in order to attack a high-value target, particularly a mobile one such as an army convoy, the attacker may be likely to travel further out of necessity.

Having identified a distance-decay, we next examined the characteristics of the offender and whether they impacted upon the distance travelled. We first tested the relationship between offender age and distance travelled. A linear regression was performed. As can be seen from the scatterplot (figure 2), age was a significant and positive predictor of distance travelled. The regression equation was: Distance travelled $=-2.969+.38 *$ age, $R^{2}=.06, \mathrm{~F}(1,231)=13.574, \mathrm{p}=.000$. For every extra year in age, we can expect an on average increase in distance travelled of .379 miles. We replicated this test with respect to 
both the IED planter and shooter sub-sets. Significant and positive associations remained for both subsets although the $R^{2}$ was markedly higher for the latter (e.g. .09 shooter vs. .05 IED).

INSERT FIGURE 2 AROUND HERE

We then conducted a number of independent-samples t-tests in order to compare the mean across the characteristics mentioned in hypotheses 2-5. Table 1 outlines these results.

INSERT TABLE 1 AROUND HERE

Shorter travel distances occurred if the offender was younger (confirming hypothesis 2), the attack targeted high value-targets (confirming hypothesis 3), if parallel terrorist activities occurred (confirming hypothesis 4) and if the attack occurred prior to PIRA's organizational restructuring (confirming hypothesis 5). With these findings in mind, we then investigated whether these factors remained significant when we disaggregated the terrorist to two role types; shooters and IED planters. The mean distance travelled for these two types of attacks approached a significant level $(p=.052)$. IED attacks, on average, involved longer distances (6.57 miles) than shooting attacks (4.45 miles). We wanted to investigate whether different factors may have different levels of impact upon both attack types. Table 3 outlines these results. Altogether, significant factors in the 
aggregate tests remained significant in these disaggregated tests apart from the impact of PIRA's re-structuring upon shooter distances.

\section{INSERT TABLE 2 AROUND HERE}

Given the previous significant findings with relation to target choice, we decided to disaggregate further. For the whole sample of offenders, Tukey post-hoc comparison tests of the four target groups illustrated that attacks that targeted civilians $(M=3.13)$ involved significantly shorter distances than those that targeted both the military $(M=$ $7.26, p<.05)$ and the police $(M=7.16, p<.05)$. There were no significant differences between civilian and government targets. This was largely replicated in the IED-planter sub-set. For example, Tukey post-hoc comparisons of the four target groups indicate that the IED events that targeted civilians $(M=3.36$ miles $)$ involved a travel distance significantly smaller than those events that targeted the military $(M=12.00$ miles, $p<$ .001) however the difference between civilian targets and police targets was only marginally significant $(M=7.79$ miles, $p=.09)$. The Tukey post-hoc comparisons also illustrated that the IED events that targeted government buildings ( $M=4.57$ miles) involved a travel distance significantly smaller than those events that targeted the military ( $M=12.00$ miles), $p<.05$. The Tukey post-hoc comparisons illustrated no significant differences once the target types are disaggregated.

For the purposes of the regression we included each of the above factors. An analysis of standard residuals was carried out, which showed that the data contained no outliers. 
Tests to see if the data met the assumption of collinearity indicated that multicollinearity was not a concern. The data met the assumption of independent errors (Durbin-Watson value $=1.30$ ). The histogram of standardized residuals indicated that the data contained approximately normally distribution of residuals. The scatter plots indicate some slight heteroscedasticity. A multiple regression was then conducted to see if any of the variables found to be significant in the bivariate tests above predicted distance travelled holding all else equal. The results are displayed in Table 3. Using the enter method it was found that the variables explained a significant amount of the variance in the distance travelled $\left(\mathrm{F}(12,191)=8.32, \mathrm{p}<.001, R^{2}=.343, R^{2}\right.$ adjusted $\left.=.302\right)$.

INSERT TABLE 3 AROUND HERE

\section{Discussion and Conclusion}

The findings contain several significant implications for both academics studying terrorist behaviour and for practitioners charged with containing the terrorist threat. Over the past few years a number of situational crime prevention informed approaches to terrorism have showed great promise. Typically, these studies focus upon the spatial and/or

temporal patterning of terrorist events. ${ }^{47}$ This study adds further credence to situational crime prevention approaches to the study of terrorism. In particular, it highlights that many of the same dynamics that influence offender decision making within the volume crime world, also apply within the terrorism realm. Five findings stand out in particular. First, a distance decay effect is identifiable. This has immediately obvious benefits for the 
practitioner in a number of ways. In the immediate aftermath of a successful terrorist attack in Northern Ireland, it highlights the likely areas the offender is likely to reside. Knowing information such as the target, the complexity of the attack, and building upon information gleaned about the appearance of the offender may help fine-tune the search process. It may also help triage between a number of potential suspects for forensic testing in the crucial hours that follow a terrorist attack. In an era of restricted policing budgets, the ability to channel finite resources towards effective investigative techniques is crucial. This study illustrates that the same principle that informs many volume crime practices can be undertaken in a terrorism context because many of the same drivers of behaviour and decision-making apply.

Second, younger offenders travel significantly lesser distances. Profiling approaches to understanding who becomes a terrorist in general have been largely abandoned because of the fact that any sample of terrorist offenders displays a great deal of heterogeneity. Our findings suggest that within such a heterogeneous sample, there may in fact be predictable behaviours amongst sub-samples and that these behaviours are largely driven by situational enablers/constraints rather than something rooted in personality.

Third, complexity matters. This is also a regular finding within the wider crime literature. There is evidence that complexity matters in terms of both the patterning of IED attacks ${ }^{48}$ and tactical choice in response to punitive counter-terrorism actions. ${ }^{49}$ Our study lends further credence to this dynamic and is a welcome move away from studies that typically posited quite static measures like ideology or root-causes as being important 
explanations. These latter explanations are beyond the ability of any practitioner to manipulate. The assumptions within the former approaches however, are highly malleable.

Fourth, our results show the ability of leading decision-makers within PIRA to impact upon the day-to-day operations of the field operatives. Shapiro's analysis of the inner dynamics workings of terrorist groups highlights the fact that leaders face a dilemma of maintaining a grip on what the soldiers do whilst minimizing communications for fear of detection. ${ }^{50}$ This dilemma makes the amount of control that leaders can actually employ over the day-to-day operations questionable. Our finding suggests that decision-making within the upper echelons of the movement can have a meaningful impact upon lower level operatives. One goal of PIRA's restructuring in the late 1970s was to make the cells engaging in daily violence more flexible and this certainly played out in terms of the greater distances travelled.

Together the results reinforce the argument that when we focus on terrorism from a preventative angle, we should focus on their behaviours: what they do rather than remain preoccupied with concerns about who they are and/or what they might be like. Collectively the results also highlight the fact that for a finer-grained understanding of terrorist behaviour we need to disaggregate on a number of levels: within the cadre of operatives, across terrorist attacks, across targets and within conflicts. Future research should seek to highlight whether any of these significant findings are generalizable beyond the confines of Northern Ireland and which are conflict-specific. Although some 
of the hypotheses generated from the volume crime literature suggest that terrorist offenders do in fact act similarly to ordinary criminals in terms of decisions regarding where they are likely to commit offences. It is also arguable that within a conflict such as Northern Ireland, where the vast majority of violence took place in a small geographic area, the maximum distances for travelling are naturally bounded. Individuals may choose to live in certain places to be close to areas high in potential targets. Unfortunately no data were available on the length of time the individual spent at the address but it is worth noting that Smith, Damphousse and Roberts found that preparatory activities for a terrorist attack typically take place closer to the target location than the offender's longtime residence. ${ }^{51}$ 
Amir, M. 1971. Patterns in Forcible Rape. Chicago, IL: The University of Chicago Press

Asal, V., Gill, P., Rethemeyer, R. K., \& Horgan, J. (2014). Killing Range

Explaining Lethality Variance within a Terrorist Organization. Journal of Conflict Resolution, 0022002713508927.

Baldwin, J. and A.E. Bottoms. 1976. The Urban Criminal: A Study in Sheffield. London: Tavistock.

Baudains, P., Braithwaite, A., \& Johnson, S. D. (2013). Target choice during extreme events: A discrete spatial choice model of the 2011 London riots. Criminology, 51(2), 251-285.

Beauregard, E., J. Proulx, K. Rossmo. 2005. Spatial patterns of sex offenders: Theoretical, empirical and practical issues. Aggression and Violent Behavior 10: 579-603.

Bernasco, W. 2010. A sentimental journey to crime: Effects of residential history on crime location choice. Criminology 48: 389-416.

Bernasco, W. and R. Block. 2009. Where offenders choose to attack: A discrete choice model of robberies in Chicago. Criminology 47: 93-130.

Bloom, M. 2005. Dying to Kill: The Allure of Suicide Terror. New York, NY: Columbia University Press.

Bloom, M., P. Gill and J. Horgan. 2012. Tiocfaidh ar Mna: Women in the Provisional Irish Republican Army. Behavioral Sciences of Terrorism and Political Aggression 4: 60-76.

Boggs, S. 1965. Urban crime patterns. American Sociological Review, 30, 899908.

Bottoms, A.E. and P. Wiles (1997) Environmental criminology. In The Oxford Handbook of Criminology, eds., M. Maguire, R. Morgan and R. Reiner. Oxford: Clarendon Press.

Braithwaite, A., \& Johnson, S. D. (2012). Space-time modeling of insurgency and counterinsurgency in Iraq. Journal of Quantitative Criminology, 28(1), 31-48.

Brantingham, P.J. and P.L. Brantingham. 1981. Environmental Criminology. Prospect Heights, IL: Waveland Press.

Briggs, X.D.S. 1998. Brown kids in white neighborhoods: Housing mobility and the many faces of social capital. Public Housing Debate 9: 177-221.

Canter, D. 2007. Mapping Murder: The Secrets of Geographical Profiling. London: Virgin.

Canter, D. and L. Hammond. 2006. A comparison of the efficacy of different decay functions in geographical profiling for a sample of US serial killers. Journal of Investigative Psychology and Offender Profiling 3: 91-103.

Capone, D.L. and W.W. Nichols. 1975. Crime and distance: An analysis of offender behaviour in space. Proceedings of the Association of American Geographers 7: 45-49.

Capone, D.L. and W.W. Nichols. 1976. Urban structure and criminal mobility. American Behavioral Scientist 20: 199-213. 
Chenoweth, E. (2013). Terrorism and Democracy. Annual Review of Political Science, 16, 355-378

Clarke, R.V. 1997. Situational Crime Prevention: Successful Case Studies. Albany, NY: Harrow and Heston Publishers.

Collins, E. 1998. Killing Rage. London: Granta Books.

Cornish, D.B., and R.V. Clarke. 1986. The Reasoning Criminal: Rational Choice Perspectives on Offending. New York: Springer-Verlag.

Deakin, J., H. Smithson, J. Spencer and J. Medina-Ariza. 2007. Taxing on the streets: Understanding the methods and process of street robbery. Crime Prevention and Community Safety 9: 52-67.

Drake, C.J.M. 1998. The role of ideology in terrorists' target selection. Terrorism and Political Violence 10:

Dugan, L. (2004). How does studying terrorism compare to studying crime? Sociology of Crime Law and Deviance, 5, 53-74.

Felson, M. 2006. Crime and Nature. Thousand Oaks, CA: Sage Publications.

Fielding, D. and Anja Shortland. 2010. “"An Eye for an Eye, a Tooth for a Tooth': Political Violence and Counter-Insurgency in Egypt". Journal of Peace Research 47(4): 433-448.

Gabor, T. and E. Gottheil. 1984. Offender characteristics and spatial mobility: An empirical study and some policy implications. Canadian Journal of Criminology and Criminal Justice 26: 267-281.

Gill, P. 2012. Assessing contemporary trends and future prospects in the study of the suicide bomber. Negotiation and Conflict Management Research 5: 239252.

Gill, P. and J. Young. 2011. Comparing role specific terrorist profiles. Paper presented at the International Studies Association annual conference, March 2011.

Goodwill, A.M. and L.J. Alison. 2007. Sequential angulation, spatial dispersion and consistency of distance attack patterns from home in serial murder, rape and burglary. Psychology, Crime \& Law 11: 161-176.

Hafez, Mohammed M. and Joseph M. Hatfield. 2006. "Do Targeted Assassinations Work?: A Multivariate Analysis of Israel's Controversial Tactic During the Al-Aqsa Uprising." Studies in Conflict and Terrorism. 29(4): 359382.

Hesseling, R.B.P. 1992. Using data on offender mobility in ecological research. Journal of Quantitative Criminology 8: 95-112.

Horgan, J. 2009. Walking Away From Terrorism. London: Routledge.

LaFree, G., \& Freilich, J. D. (2012). Editor's introduction: quantitative approaches to the study of terrorism. Journal of Quantitative Criminology, 28(1), 1-5.

Lafree, Gary, Laura Dugan and Raven Korte. 2009. "The Impact of British Counterterrorist Strategies on Political Violence in Northern Ireland: Comparing Deterrence and Backlash Models." Criminology 47(1): 17-45.

Le Beau, J.L. 1987. The journey to rape: Geographic distance and the rapist's method of approaching the victim. Journal of Police Science and Administration 15: 129-36. 
Lundrigan, S. and S. Czarnomski. 2006.. Austrialian and New Zealand Journal of Criminology 39: 218-231.

Lyall, Jason. 2009. "Does Indiscriminate Violence Incite Insurgent Attacks? Evidence from Chechnya". Journal of Conflict Resolution 53(3): 331-362.

Meaney, R. 2004. Commuters and marauders: An examination of the spatial behaviour of serial criminals. Journal of Investigate Psychology and Offender Profiling 1: 121-137.

O’Doherty, S.P. 2008. The Volunteer. New York: Strategic Books Publishing.

Pape, R. 2005. Dying to Win: The Strategic Logic of Suicide Terrorism. New York: Random House Publishers.

Rand, A. 1986. Mobility triangles. In Metropolitan Crime Patterns, eds. R.M. Figlio, S. Hakim \& G.F. Rengert. Monsey, NY: Criminal Justice Press

Rattner, A. and B.A. Portov. 2007. Distance decay function in criminal behaviour. A case of Israel. The Annals of Regional Science 41: 673-688.

Rengert, G. 1975. Some effects of being female on criminal spatial behaviour. $P a$. Geographer 13: 10-18.

Rengert, G.F., A.R. Piquero and P.R. Jones. 1999. Distance decay re-examined. Criminology 37:427-445.

Repetto, T. 1974. Residential Crime. Cambridge, MA: Ballinger.

Rhodes, W.M. and C. Conly. 1981. Crime and mobility: An empirical study. In Environmental Criminology, eds. P.J. Brantingham and P.L. Brantingham. Beverly Hills, CA: Sage.

Turner, S. 1969. Delinquency and distance. In Delinquency: Selected Studies, eds. T. Sellin and M.E. Wolfgang. New York: Wiley.

van Koppen, P.J. and J.W. de Keijser. 1997. Desisting distance decay: On the aggregation of individual crime trips. Criminology 35: 505-515.

Warren, J., R. Reboussin, R.R. Hazelwood, A. Cummings, N. Gibbs and S. Trumbetta. 1998. Crime scene and distance correlates of serial rape. Journal of Quantitative Criminology 14: 35-59.

White, R.C. 1932. The relation of felonies to environmental factors in Indianapolis. Social Forces 10: 498-509.

White, R.W., and T.F. White. 1991. Revolution in the city: On the resources of urban guerrillas. Terrorism and Political Violence 3: 100-132.

Wikstrom, P-O. 1985. Everyday violence in contemporary Sweden: Situational and ecological aspects. Research Report for the National Council for Crime Prevention, Sweden. Stockholm: Ministry of Justice.

Wright, R., and S. Decker. 1997.. Boston: Northeastern University Press.

Wright, R., F. Brookman and T. Bennett. 2006. The foreground dynamics of street robbery in Britain. British Journal of Criminology 46: 1-15.

Zipf, G.K. 1965. Human Behavior and the Principle of Least Effort: An Introduction to Human Ecology. New York: Hafner. 
${ }^{1}$ O'Rawe, Richard. Blanketmen: An untold story of the H-Block hunger strike. Virago Press, 2005.

2 Townsley, Michael, and Aiden Sidebottom. "All offenders are equal, but some are more equal than others: Variation in journeys to crime between offenders." Criminology 48, no. 3 (2010): 897-917.

${ }^{3}$ Canter, David, and Paul Larkin. "The environmental range of serial rapists." Journal of Environmental Psychology 13, no. 1 (1993): 63-69.

${ }^{4}$ Baldwin, John, Anthony E. Bottoms, and Monica A. Walker. The urban criminal: A study in Sheffield. Vol. 159. Tavistock Publications, Limited, 1976; Boggs, Sarah L. "Urban crime patterns." American Sociological Review (1965): 899-908; Goodwill, Alasdair M., and Laurence J. Alison. "Sequential angulation, spatial dispersion and consistency of distance attack patterns from home in serial murder, rape and burglary." Psychology, Crime \& Law 11, no. 2 (2005): 161-176; Hesseling, Rene BP. "Using data on offender mobility in ecological research." Journal of Quantitative Criminology 8, no. 1 (1992): 95-112; Meaney, Rebecca. "Commuters and marauders: An examination of the spatial behaviour of serial criminals." Journal of Investigative Psychology and Offender Profiling 1, no. 2 (2004): 121-137.

${ }^{5}$ LaFree, G., \& Dugan, L. (2004). How does studying terrorism compare to studying crime. Terrorism and counter-terrorism: Criminological perspectives, 53-74; LaFree, Gary, and Joshua D. Freilich. "Editor's introduction: quantitative approaches to the study of terrorism." Journal of Quantitative Criminology 28, no. 1 (2012): 1-5.

${ }^{6}$ Taylor, Max. The Terrorist. Brassey's Defence Publishers, 1988.

${ }^{7}$ Horgan, John. Walking away from terrorism: Accounts of disengagement from radical and extremist movements. Routledge, 2009, pp143.

${ }^{8}$ Cornish, Derek B., and Ronald V. Clarke, eds. The reasoning criminal: Rational choice perspectives on offending. Transaction Publishers, 2014.

${ }_{9}^{9}$ Beauregard, Eric, Jean Proulx, and D. Kim Rossmo. "Spatial patterns of sex offenders: Theoretical, empirical, and practical issues." Aggression and Violent Behavior 10, no. 5 (2005): 579-603.

${ }^{10}$ Pape, R. (2005). Dying to win: The strategic logic of suicide terrorism. Random House.

${ }^{11}$ Drake, Charles JM. "The role of ideology in terrorists' target selection." Terrorism and Political Violence 10, no. 2 (1998): 53-85. Pp53.

12 Perliger, Arie, Gabriel Koehler-Derrick, and Ami Pedahzur. "The Gap Between Participation and Violence: Why We Need to Disaggregate Terrorist 'Profiles'." International Studies Quarterly (2016).

${ }^{13}$ Gill, Paul, and Joseph K. Young. "Comparing role-specific terrorist profiles." Available at SSRN 1782008 (2011).

${ }^{14}$ Bernasco, Wim, and Richard Block. "Where offenders choose to attack: A discrete choice model of robberies in Chicago." Criminology 47, no. 1 (2009): 93-130. Pp95

${ }^{15}$ Horgan, John, and Max Taylor. "The provisional Irish Republican army: Command and functional structure." Terrorism and Political Violence 9, no. 3 (1997): 1-32. 
${ }^{16}$ Amir, Menachem. Patterns in forcible rape. Chicago: University of Chicago Press, 1971.

${ }^{17}$ LeBeau, James L. "The journey to rape: Geographic distance and the rapist's method of approaching the victim." Journal of Police Science \& Administration (1987).

${ }^{18}$ Warren, Janet, Roland Reboussin, Robert R. Hazelwood, Andrea Cummings, Natalie Gibbs, and Susan Trumbetta. "Crime scene and distance correlates of serial rape."

Journal of Quantitative Criminology 14, no. 1 (1998): 35-59.

${ }^{19}$ Deakin, Jo, Hannah Smithson, Jon Spencer, and Juanjo Medina-Ariza. "Taxing on the streets: Understanding the methods and process of street robbery." Crime Prevention \& Community Safety 9, no. 1 (2007): 52-67; Wright, Richard, Fiona Brookman, and Trevor Bennett. "The foreground dynamics of street robbery in Britain." British Journal of Criminology 46, no. 1 (2006): 1-15; Wright, Richard T., and Scott H. Decker. Armed robbers in action: Stickups and street culture. UPNE, 2011.

${ }^{20}$ Zipf, George Kingsley. Human behavior and the principle of least effort: An introduction to human ecology. Ravenio Books, 2016.

${ }^{21}$ Lundrigan, Samantha, and Sarah Czarnomski. "Spatial characteristics of serial sexual assault in New Zealand." Australian \& New Zealand Journal of Criminology 39, no. 2 (2006): 218-231. Pp220.

${ }^{22}$ See Bernasco and Block, footnote 14, pp99

${ }^{23}$ Bloom, Mia. Dying to kill: The allure of suicide terror. Columbia University Press, 2005.

${ }^{24}$ Canter, David, and Laura Hammond. "A comparison of the efficacy of different decay functions in geographical profiling for a sample of US serial killers." Journal of Investigative Psychology and Offender Profiling 3, no. 2 (2006): 91-103; Rattner, Arye, and Boris A. Portnov. "Distance decay function in criminal behavior: a case of Israel." The Annals of Regional Science 41, no. 3 (2007): 673-688; Rengert, George. "The journey to crime." Punishment, places and perpetrators: Developments in criminology and criminal justice research (2004): 169-81; Rhodes, William M., and Catherine Conly. "Crime and mobility: An empirical study." Environmental criminology (1981): 167-188.

${ }^{25}$ See Beauregard et al., footnote 9, pp582

${ }^{26}$ Rossmo, D. Kim, and Keith Harries. "The geospatial structure of terrorist cells." Justice Quarterly 28, no. 2 (2011): 221-248.

${ }^{27}$ Smith, Brent L., Jackson Cothren, Paxton Roberts, and Kelly R. Damphousse. "Geospatial analysis of terrorist activities: The identification of spatial and temporal patterns of preparatory behavior of international and environmental terrorists." $U S$ Department of Justice (2008).

${ }^{28}$ Beauregard et al., footnote 9

${ }^{29}$ Wikström, Per-Olof H., and Suède. Brottsförebyggande rådet. Everyday violence in contemporary Sweden: Situational and ecological aspects. National Council for Crime Prevention, Sweden, Research Division, 1985.

${ }^{30}$ Goodwill and Allison, see footnote 4, pp174

31 de Souza Briggs, Xavier. "Brown kids in white suburbs: Housing mobility and the many faces of social capital." Housing policy debate 9, no. 1 (1998): 177-221.

32 Parkin, William S., and Joshua D. Freilich. "Routine activities and right-wing extremists: An empirical comparison of the victims of ideologically-and non- 
ideologically-motivated homicides committed by American far-rightists." Terrorism and Political Violence 27, no. 1 (2015): 182-203; Parkin, William S., Joshua D. Freilich, and Steven M. Chermak. "Ideological Victimization Homicides Perpetrated by Far-Right Extremists." Homicide studies 19, no. 3 (2015): 211-236.

${ }^{33}$ Capone, Donald L., and Woodrow W. Nichols. "Crime and distance: An analysis of offender behavior in space." In Proceedings of the Association of American Geographers, vol. 7, no. 1, pp. 45-49. 1975; Gabor, Thomas, and Ellen Gottheil. "Offender characteristics and spatial mobility: An empirical study and some policy implications." Canadian J. Criminology 26 (1984): 267; KOPPEN, PETER J., and JAN W. KEIJSER. "Desisting distance decay: On the aggregation of individual crime trips." Criminology 35, no. 3 (1997): 505-515.

${ }^{34}$ Horgan and Taylor, see footnote 15

${ }^{35}$ Gill, Paul, Jeongyoon Lee, Karl R. Rethemeyer, John Horgan, and Victor Asal. "Lethal connections: The determinants of network connections in the Provisional Irish Republican Army, 1970-1998." International Interactions 40, no. 1 (2014): 52-78.

${ }^{36}$ Bloom, Mia, Paul Gill, and John Horgan. "Tiocfaidh ar mna: women in the Provisional Irish Republican Army." Behavioral Sciences of Terrorism and Political Aggression 4, no. 1 (2012): 60-76.

${ }^{37}$ Horgan and Taylor, see footnote 15

${ }^{38}$ Coogan, Tim Pat. The IRA. Palgrave Macmillan, 2002.

${ }^{39}$ Gill, Paul, and John Horgan. "Who Were the Volunteers? 1 The Shifting Sociological and Operational Profile of 1240 Provisional Irish Republican Army Members." Terrorism and political Violence 25, no. 3 (2013): 435-456.

${ }^{40}$ IBID

${ }^{41}$ Gill et al., see footnote 35

${ }^{42}$ McKittrick, David. Lost Lives: The stories of the men, women and children who died as a result of the Northern Ireland troubles. Random House, 2001.

${ }^{44}$ Asal, Victor, Paul Gill, R. Karl Rethemeyer, and John Horgan. "Killing range explaining lethality variance within a terrorist organization." Journal of Conflict Resolution (2013): 0022002713508927.

${ }^{45}$ Canter, David. Mapping murder: the secrets of geographical profiling. Random House, 2007.

46 Townsley and Sidebottom, see footnote 2.

${ }^{47}$ LaFree, Gary, Laura Dugan, Min Xie, and Piyusha Singh. "Spatial and temporal patterns of terrorist attacks by ETA 1970 to 2007." Journal of Quantitative Criminology 28, no. 1 (2012): 7-29; Braithwaite, Alex, and Shane D. Johnson. "Space-time modeling of insurgency and counterinsurgency in Iraq." Journal of Quantitative Criminology 28, no. 1 (2012): 31-48; Siebeneck, Laura K., Richard M. Medina, Ikuho Yamada, and George F. Hepner. "Spatial and temporal analyses of terrorist incidents in Iraq, 20042006." Studies in Conflict \& Terrorism 32, no. 7 (2009): 591-610.

${ }^{48}$ See Braithwaite and Johnson, footnote 47

${ }^{49}$ See Asal et al., footnote 44

${ }^{50}$ Shapiro, Jacob N. The Terrorist's Dilemma: Managing violent covert organizations. Princeton University Press, 2013. 
${ }^{51}$ See Smith et al., footnote 27 